\title{
Study on College Students Extracurricular Physical Exercise and Mental Health
}

\author{
Xianfu Wang \\ School of Physical Education, Zhengzhou Institute of Technology \\ E-mail: tuke126@126.com \\ *Corresponding Author:Xianfu Wang
}

Keywords: College students, extracurricular physical exercise, psychological health, comparison

\begin{abstract}
College students faced the increasing pressure on learning, employment, economic, and emotional aspects, and inevitably had various psychological problems and abnormal behavior. How to alleviate psychological pressure and adjust mental status had become a problem to be solved in real life. Through experimental method and questionnaire survey method, students were organized designedly for the control experiment which were extracurricular physical exercise one hour per week (control group)and extracurricular physical exercise one hour per day (experimental group). Comparative control study were performed on events difference influence on college students psychological health aspects.
\end{abstract}

\section{Introduction}

At present, the social environment, family environment and school environment that college students faced became more and more complex. Many psychological disorders could cause college students unable finalize the college education and increased the proportion of aggressive behavior, malicious harm, even suicide act [1]. College students mental health education was the current significant task in front of higher education institutes. Therefore, it required to profoundly investigate and analyze college students psychological health condition and physical exercise condition and their mutual correlation [2-4]. Experimental verification was necessary to study the specific mechanism of physical exercise on relieve college students psychological pressure. SCL-90 was applied in this study for comparative control study on the influence of physical exercise time difference on college students psychological health.

\section{Study objective and methods}

\subsection{Study objective}

As per the study requirement, 300 enrolled students in 2015 were randomly selected from Hebei University of Water Resources and Electric Engineering. This students were randomly divided into experimental group and control group. Each group had 150 students.

\subsection{Study method}

Experimental method and questionnaire survey method were adopted. The experiment was performed under the designed guidance. Experimental group had the extracurricular physical exercise one hour per day. Control group had the extracurricular physical exercise one hour per week. SCL-90 psychological condition questionnaire were employed for the comparative control study on the psychological level of experimental group and control group. Mathematical statistics method and EXECL 2003 office software were used for data processing. The SPSS 11.0 statistical software were used as well. Difference represent method were $*$ represented $<0.05, * *$ represented $<0.01$, *** represented $<0.001$.

\section{Results and Analysis}

Somatization study results put that the psychological health level on somatization factor aspects in experimental objectives was apparently higher than national youth norm level. Furthermore, experiment group was significantly higher than control group, as seen in table 1 . In the obsessive-compulsive factor aspect of psychological health level, experiment group was 
significantly higher than national youth norm level. Control group was lower than national youth norm level, which had certain psychological problems. Experimental group was obviously higher than control group, as seen in table 2. In interpersonal sensitivity sensitivity factor aspect, control group level was same as national youth norm level. Experiment group was apparently higher than national youth norm level. While, experiment group was significantly higher than control group, as shown in table 3. Depression symptom study results showed that the psychological health level in control group was same as national youth norm level. Depression symptom results was shown in table 4. In depression factor aspect in psychological health level, control group was in the same level of national youth norm level. Experiment group level was significantly higher than national youth norm level. Further more, experiment group was higher than control group. Anxiety symptoms results was shown in table 4. In anxiety factor aspect of psychological health level, control group was in the same level of national youth norm level. Experiment group was apparently higher than national youth norm level. And experiment group was much higher than control group. The below factors were similar as anxiety factor, such as hostility factor, photic anxiety factor, paranoididefition factor and psychotieism. In additional items and other items. There were 7 item which were excluded in any factor. During the analysis, these were considered as the $10^{\text {th }}$ factor in this study, so as the summary of factors could equal to the overall scores. It could also reflect the sleep and food condition. Results showed that the positive influence of the 7 factors in experiment was obviously higher than control group, as seen in table 5 . The general symptomatic index study results were shown in table 6. The comprehensive mental health level in control group stood in the same level of national youth norm level. Further more, the experiment group was obviously higher than national youth norm level.

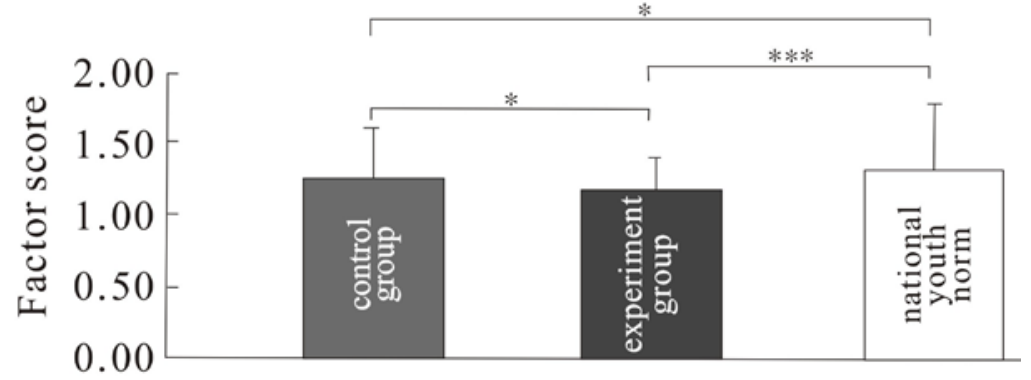

Pic 1. SCL-90 somatization factor

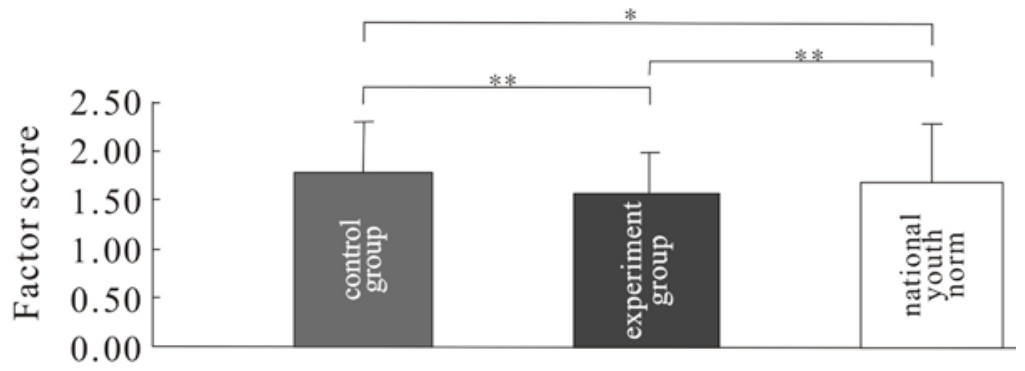

Pic 2. SCL-90 obsessive-compulsive factor

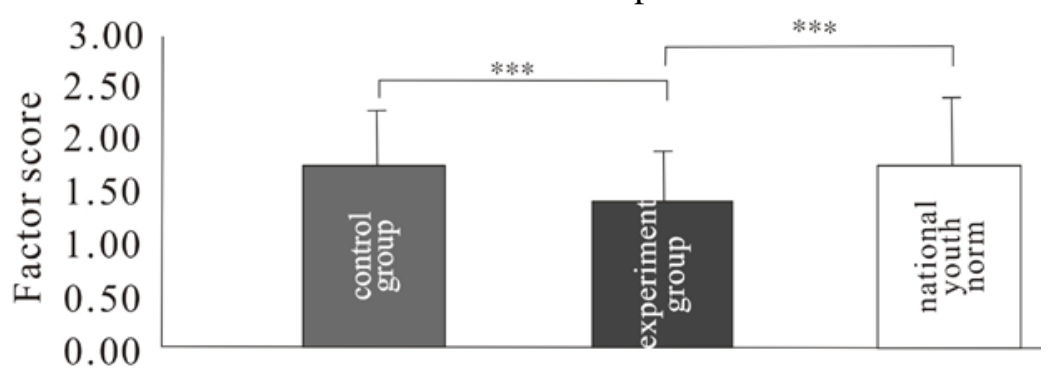

Pic 3. SCL-90 Interpersional sensitivity factor 


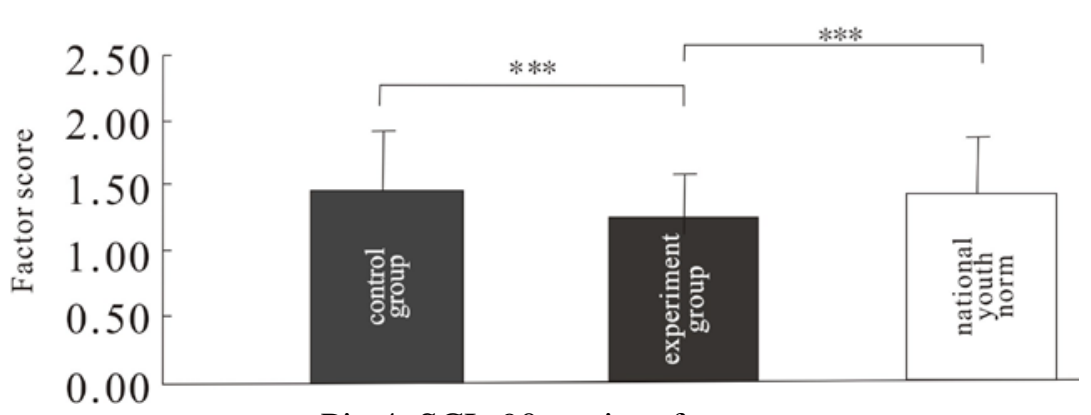

Pic 4. SCL-90 anxiety factor

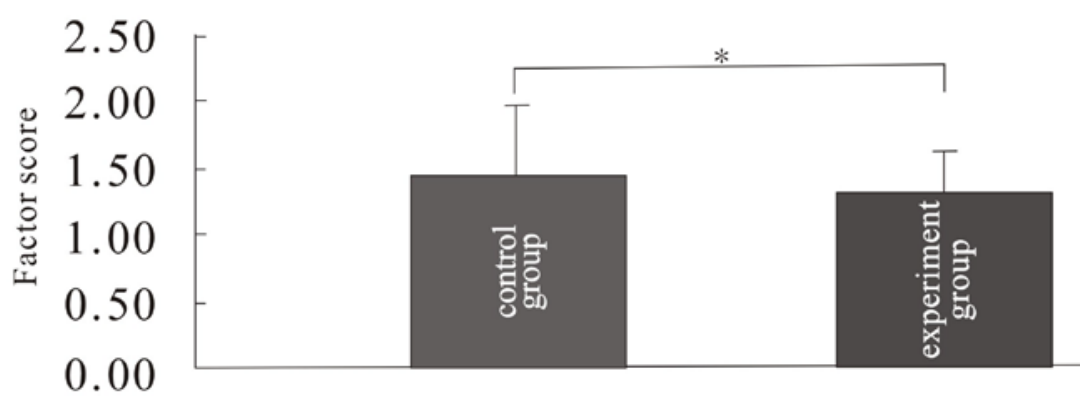

Pic 5. SCL-90 Additional items factor

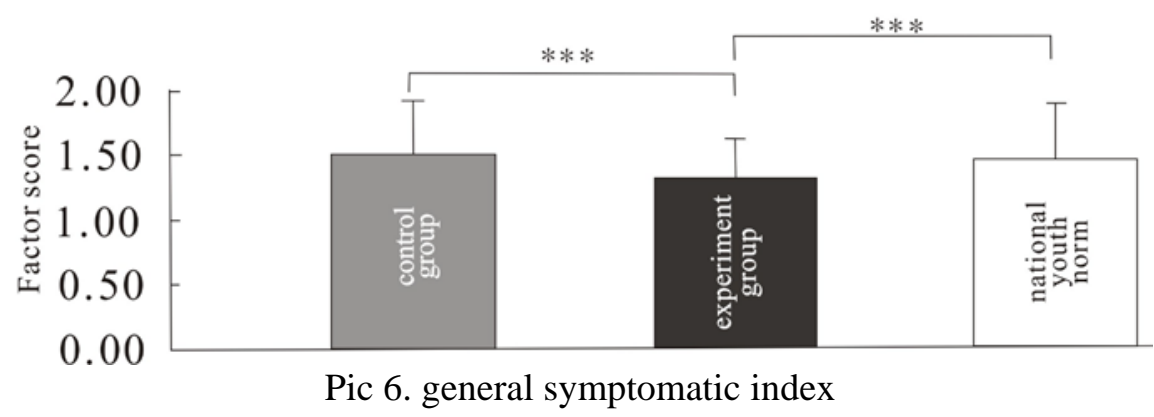

\section{Conclusion}

Physical exercise could promote college students more reasonably and rationally face the problems in daily life. In addition, the extracurricular physical exercise in general college was performed in a certain society environment [5]. Extracurricular physical exercise always had direct or indirect connection and communication with college students. College students could gradually forgot the trouble and pain during the physical exercise, and expand their social interaction, and coordinate the interpersonal relationship, thus enhance the social adaptation ability.

The average score of crowd symptom factor for students participating physical exercise one hour per day was lower than whom participating physical exercise one hour per week. The scientific statistical tests confirmed that it had significant difference on the average scores on obsessive-compulsive factor, anxiety and hostility factor between students participating physical exercise one hour per day and students participating physical exercise one hour per week. It had significant difference through statistical test. The positive detection rate of depression factor, interpersonal sensitivity factor, anxiety factor, hostility factor, photic anxiety factor, paranoididefition factor and psychotietism factor in experiment group was apparent lower than these factor in control group. The stability of psychological condition factor and emotional factor in experiment group was much better than that in control group. But, there was no significant difference. Thus, participating in extracurricular physical exercise could improve and enhance the level of psychological health of college students.

\section{1 strengthen the college students' physical exercise awareness on psychological health}

In the reform of school physical education curriculum system, the education concept should be modulated, and cover philosophy, biology, psychology, morality and physical health. The psychological health education should be strengthened and combined with physical exercise[6]. The content included comprehensive development structure requirement of psychological health, 
correlation of physical exercise class and extracurricular physical exercise, unification study of physical exercise class and extracurricular physical exercise and the overall optimization of physical exercise curriculum content and method. The current physical education class and extracurricular exercise education content shall be updated. And other content shall be added in, such as bodybuilding, fitness, national traditional sports and necessary physical education material for modern life. The combination of physical education theory and practice shall be paid more attention on. At the same time, it should strengthen the psychological health education of college students physical education center and added certain education material of physical education and sport hygiene. Some basic theory knowledge which was suitable for college students application and master shall be added, such as handling and prevention of sports injuries, sports health guidance, health routine and measures of physical exercise, psychological health concept and the promotion function of physical exercise on psychological health [7]. This common sense shall be involved in physical education education process, and enable college students really and pragmatically understand the relation of physical exercise and psychological health, master necessary physical hygiene basic theory knowledge and basic practice, and correctly apply on the physical exercise practice in future, and lay a foundation for the lifetime sports.

\subsection{South Central Agricultural Colleges and Universities Students strengthen awareness of physical activity to promote mental health function}

South Central Agricultural Colleges and Universities focus on reform of school PE curriculum system should be in the changing concepts of education, we should cover philosophical, biological, physical, mental, moral, physical health and all disciplines, to strengthen mental health education efforts to make physical and health education combined to the "health sports" road.Its content includes the study of physical and mental development of a comprehensive structural requirements to study physical education and after-school physical activity relationship studies and physical education curricular sports activities inside and outside the unified, global optimization study contents and methods of physical education curriculum and the like. Update existing physical education teaching contents and curricular sports activities, increasing portion bodybuilding, fitness, traditional sports and modern life requires sports teaching materials, pay attention to the combination of theory and practice sports.But also to strengthen the PE Teaching Students Mental Health Education, Sport Health additional teaching certain content. Select some sports health basic theoretical knowledge for undergraduate students to apply and master: such as sports injury treatment and prevention, sports health instruction, physical training in health law and measures to promote the role of Mental Health Concept and Physical Training on Mental Health, etc. , these basics and into the physical education teaching process, so that students real, effective understanding of physical exercise and mental health of the relationship, have the necessary physical health care basic theoretical knowledge and basic skills, and in the future to participate in physical exercise practice can proper use, laying the foundation for the "lifetime Sports.

\section{2 combination of psychological counseling and extracurricular physical activities}

The leadership of various functional departments in college, especially the college students management department and related personnel shall take a certain organizational and reasonable effective methods to strengthen students' awareness and understandings on extracurricular physical exercise promoting psychological health function, arouse the interest to participate in extracurricular physical exercise, and form the habit of consciousness to involve in extracurricular physical exercise, so as to maximally relieve various of psychological pressure from society and family. It could comprehensively improve the physical and mental health to achieve mental health function. Although participating in extracurricular physical exercise on mental health had obvious improvement effect, it could not completely replace the psychological consultation. Colleges should carry out more small scale and variety of extracurricular physical exercise project and the psychological consultation department, fully utilize campus network, campus newspaper, publicity column, radio stations and other media. The proper mental guidance could enable college students understand after-study physical exercise could promote students psychological health development. In addition, it should carry out publicity and education on extracurricular physical knowledge lectures, make college students develop a good habit of physical exercise, and cultivate the interest in physical exercise and improve the college students to participate in physical exercise class. 


\section{References}

[1] Xiaohong Zhang, Liqin Shen, Mei Li. The relations between sports activities habit and psychological healthy of middle school students. Journal of Chengdu Physical Education Institute. Vol. 28, No. 4, p.34-35. (2002)

[2] Yi Qu. Sports and psychological health of the young students. Journal of Wuhan Institute of Physical Education. Vol. 37, No. 1, p. 25. (2003)

[3] Ning Yan, Rongjian Mao, Zhixiong Mao. Effects of physical activities and physical training on emotion. Journal of Beijing University of Physical Education, Vol. 26, No. 1, p. 30-32. (2003)

[4] Yaran An, Chenglin Zhou, Yuchen Yang, Shubo Pan. Investigation and countermeasures on mental health of normal university students in liaoning province. China Sports Science and Technology. Vol. 37, No. 7, p. 31-35. (2001)

[5] Hongying Han. Application study of physical exercise therapy on students extracurricular physical exercise. Journal of Qinghai University(Nature Science). Vol. 23, No. 6, p. 79-81. (2005)

[6] Haiyan Liu, Zhaogang Tong, Jun Yan. Different intensity aerobics of varying timeon self-efficacy and psychological health of female collegians. Journal of Xi'an Physical Education University. Vol. 24, No. 1, p. 125-130. (2007)

[7] Qiuli Chen, Shuibao Zhai. Research on the intervention effects of body-building walk and run on college students' social physical anxiety. Journal of Beijing Sports University. Vol. 30, No. 8, p. 10511053. (2007) 